AperTO - Archivio Istituzionale Open Access dell'Università di Torino

\title{
Insects as Raw Materials in Compound Feed for Aquaculture
}

\section{This is the author's manuscript}

Original Citation:

\section{Availability:}

This version is available http://hdl.handle.net/2318/1669290

since 2019-12-24T13:01:27Z

Publisher:

Halloran A., Flore R., Vantomme P., Roos N.

Published version:

DOI:10.1007/978-3-319-74011-9_16

Terms of use:

Open Access

Anyone can freely access the full text of works made available as "Open Access". Works made available under a Creative Commons license can be used according to the terms and conditions of said license. Use of all other works requires consent of the right holder (author or publisher) if not exempted from copyright protection by the applicable law. 


\title{
Insects as Raw Materials in Compound Feed for Aquaculture
}

\begin{abstract}
Already in the early phases of the development of an European insect industry, aquafeed was suggested as one of the first animal feeds where insect products could be implemented. Since then, substantial progress has been made by the research community and feed producers to test various types of insect species and insect products as part of a complete feed for aquaculture. These (mostly extruded) feeds are typically high in energy and protein content which demands specifics characteristics of the raw materials. The role insects, high in protein and lipids, can play in these diets will be reviewed and discussed in this chapter. We will shortly touch on topics like the effect of insect feeding substrate, insect processing and chitin that all can have an effect on insect meal. Finally, feed safety considerations related to the use of insects in aquafeeds will be reviewed and discussed.

\section{Introduction}

Compound feed contains macro- and micronutrients in levels that fulfil the animal's requirements for healthy growth under intensive rearing conditions. Compound feed normally contains animal- and/or plant-based feed materials to which micronutrients (vitamins, minerals) are added. The most used feed ingredients are fishmeal, krill meal, soy protein concentrate, corn gluten meal, wheat gluten, fish oil and rapeseed oil amongst others. Animal by-products, like feather meal or blood meal are also used (not in Norway) and novel feed materials are investigated like, seaweed, microalgae, bacterial protein meal and insects. Diets for carnivorous fish like

E.-J. Lock $(\square)$

National Institute of Nutrition and Seafood Research (NIFES), Bergen, Norway

e-mail: elo@nifes.no

\section{Biancarosa}

National Institute of Nutrition and Seafood Research (NIFES)-University of Bergen,

Bergen, Norway

e-mail: ibi@nifes.no

\section{Gasco}

Università degli studi di Torino, Torino, Italy

e-mail: laura.gasco@unito.it 
rainbow trout (Oncorhynchus mykiss) and Atlantic salmon (Salmo salar) are high-energy diets, characterized by high contents of lipids and protein, and low levels of carbohydrates. Animal-based feed ingredients, like insects, fit these constraints much better then vegetable-based feed ingredients. The nutrient content of various insect species has been widely studied and is reviewed in several articles (Rumpold and Schluter 2013; Barroso et al. 2014; Makkar et al. 2014; SanchezMuros et al. 2014; Henry et al. 2015). Fish prey on insects in their natural environment and to include insects in a compound feed is self-evident from a natural perspective. However, also from a nutritional perspective insects can be a valuable feed ingredient and will be discussed in the following sections.

\section{Inclusion of Insect Raw Materials in Compound Feed for Fish}

A large number of insect species can potentially be considered for their inclusion in fish diets. However, the interest towards the use of insect ingredients in aquafeeds focusses mainly around a few insect species that can be produced on a large scale. The investigations conducted so far mainly concern the use of larvae meals obtained from Tenebrio molitor (TM), Hermetia illucens (HI) and Musca domestica (MD). While a relatively large number of research articles exists on insect meals in warm water fish species (Henry et al. 2015), very few studies have investigated the effects of insect meals (IM) in salmonids (Table 1) or marine species (Table 2).

The results of the existing studies differ, depending on fish species considered, IM inclusion levels and types, and feed formulation. Including a new ingredient means replacement of another ingredient in the diet. In most studies, fishmeal (FM) is replaced; however other studies replaced plant-based ingredients, resulting in not directly comparable results. Finally, a replacement of FM by IM is often expressed as \% replacement of FM. Since the amount of FM varies between studies, direct comparisons on \% replacement is not always possible.

\subsection{Growth Performance and Feed Utilisation}

The use of IM in salmonid diets was already investigated in the 1980s (Akiyama et al. 1984) with the aim of stimulating feed ingestion or palatability. A part of the FM was substituted by low levels (5\%) of silkworm pupae or earthworm powder in swim-up fry diets. The use of earthworm powder resulted in a weight gain (WG) and feed efficiency improvement of 30\% and 39\% respectively. Silkworm meal slightly improved feed efficiency while neither source increased the palatability of the fish diet, measured as daily food consumption. 


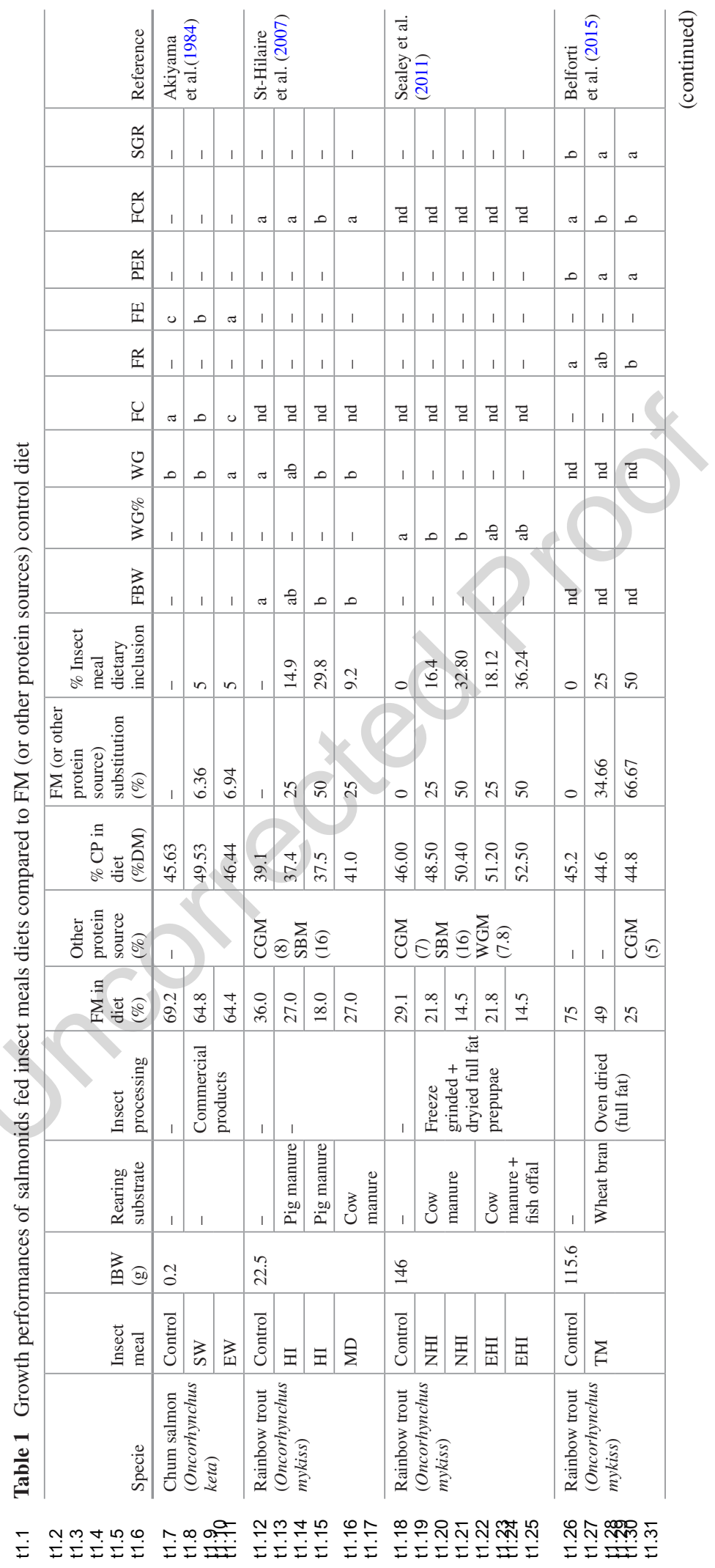




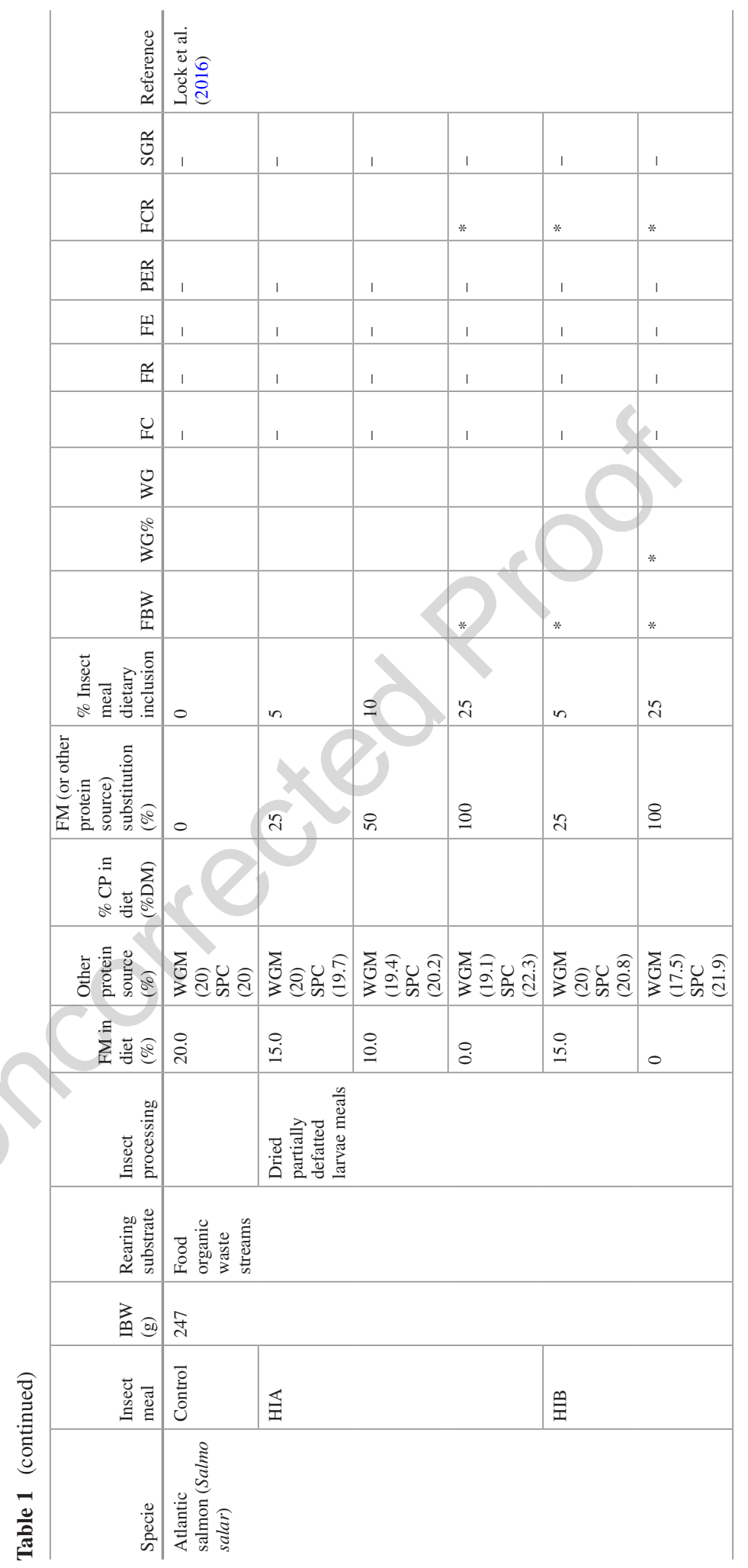

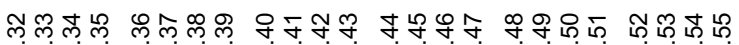
FEFE FEFE FEFE EFEE 


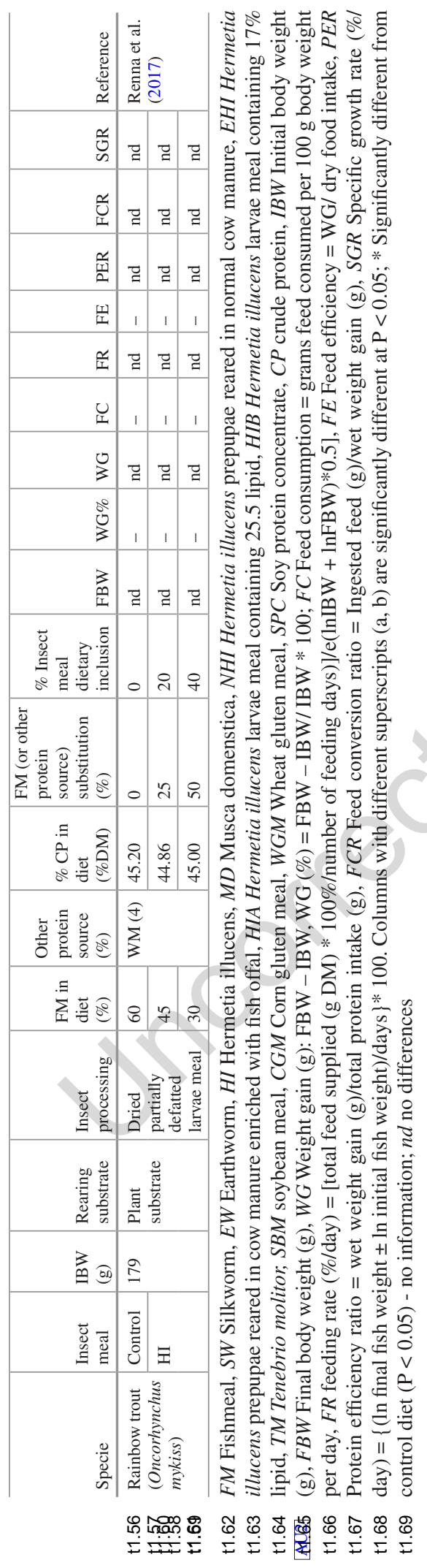




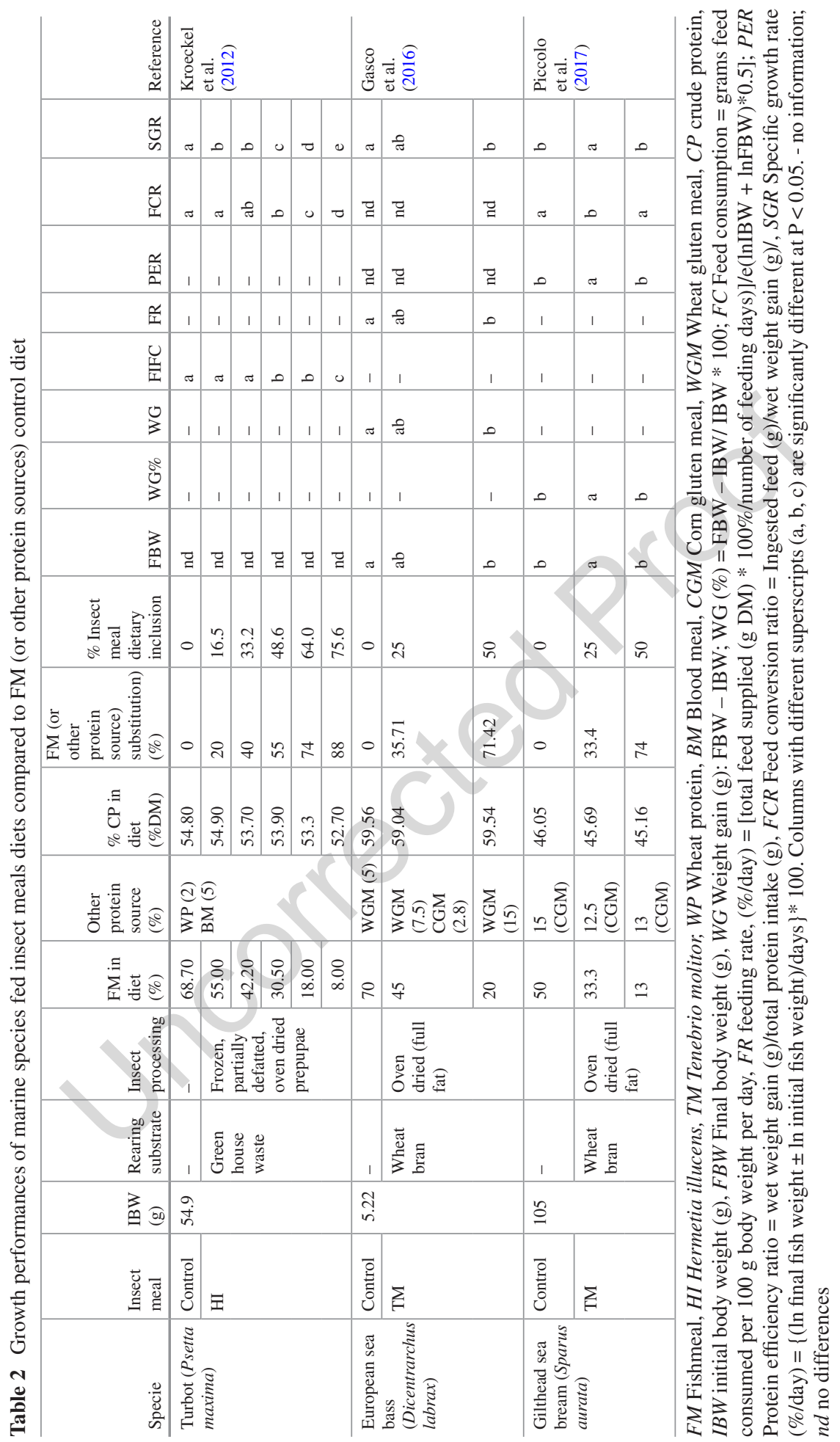


St-Hilaire et al. (2007) investigated the use of a full fat pre-pupae HI meal used in partial substitution of FM and fish oil (FO) in the diet of rainbow trout. HI meal was included at two levels (15 and 30\%) leading to a FM substitution of $25 \%$ and $50 \%$ and to a FO substitution of 36 and $72 \%$ respectively. No significant differences on growth performances were reported at the lowest level of inclusion allowing a valuable FO saving. St-Hilaire et al. (2007) suggested that above this level, the chitin contained in the pre pupae may have decreased the digestibility, thus the availability of nutrients, resulting in lower fish performances. On the other hand, the dietary inclusion of $\mathrm{HI}$ meal lead to a modification of the dietary fatty acid profile (increase and decrease of saturated and polyunsaturated fatty acids respectively) that could have influenced lipid digestibility. In the same trial, authors studied the effects of a whole MD larvae meal included at 9.2\% in the fish's diet (25\% of FM substitution). The inclusion resulted in a decrease of production parameters (St-Hilaire et al. 2007). Renna et al. (2017) showed that a partially defatted HI larvae meal can be used as feed ingredient in rainbow trout diets up to $40 \%$ of inclusion level (50\% of FM substitution) without impacting growth performance. Sealey et al. (2011) highlighted the possible influence of larva rearing substrate on the quality of the insect meal in a trial with rainbow trout. IM produced from HI larvae fed a diet enriched with fish offal performed better than IM produced from HI larvae fed a diet without the fish offal enrichment. Rainbow trout fed a diet with the enriched HI meal (at 50\% FM replacement) performed equally well as the control FM based diet, whilst the non-enriched HI meal performed less at already $25 \% \mathrm{FM}$ replacement.

A full fat TM larvae meal was tested as a FM substitution (up to 50\%) in rainbow trout diets by Belforti et al. (2015). No significant changes in fish performance parameters were found up to 50\% FM replacement. A reduced voluntary feed intake was reported with the increase of TM meal. The effects of dietary FM replacement $(0,25 \%, 50 \%$ and $100 \%)$ by super worm (Zophobas morio) meal on rainbow trout fingerlings growth performance was investigated by Doğankaya (2017). Fish fed diets containing up to $25 \%$ of FM substitution performed better than the fish fed the control diet, while no differences were observed between $0 \%$ and $50 \%$ of FM substitution. Highest IM level induced a dramatic worsening in performance parameters.

Concerning marine species, Kroeckel et al. (2012) tested partially defatted HI prepupae meal in diets of juvenile turbot (Psetta maxima), and found a general worsening of performances at the inclusion levels higher than 33\%. Moreover, authors found a decrease of feed intake with increasing HI meal incorporation, due to low palatability. Authors suggested that the presence of chitin might have influenced the feed intake, availability, and digestibility of the nutrients and therefore growth performance. Nevertheless, as HI was produced on local greenhouse waste streams, the authors concluded that it could be a sustainable alternative protein source in partial substitution of FM (Kroeckel et al. 2012). Karapanagiotidis et al. (2014) evaluated a pre-pupae full fat HI meal (crude protein, CP: 31.6\%; either extract, EE: 27.2) in gilthead seabream (Sparus aurata) diets. Four diets were formulated substituting FM $(0,9 \%, 17 \%$ and $25 \%)$ with $\mathrm{HI}$ meal at $0 \%, 9.5 \%, 19.4 \%$ 
and $27.6 \%$ of $\mathrm{HI}$ inclusion. Fish fed diets containing HI meal recorded a significant decrease in final fish weight and WG due to a significant decrease of total feed consumption. On the other hand, feed conversion rate (FCR), protein efficiency ratio (PER) and protein retention as well as specific growth rate (SGR) parameters did not show differences among treatments.

Gasco et al. (2016) evaluated the effects of dietary inclusion of a full-fat TM larvae meal on European sea bass (Dicentrarchus labrax) juveniles. Dietary TM meal inclusion level of 50\% led to a worsening of final body weight, WG, SGR and feeding rate (FR). Using the same substitution protocol and the same full-fat TM larvae meal, Piccolo et al. (2017) found improved final weight, SGR, PER and FCR in fish fed $25 \%$ of TM meal dietary inclusion.

The importance of insect processing becomes evident in a study by Lock et al. (2016). Two different HI meals (IMA and IMB), obtained through different nutrient isolation and processing techniques, were evaluated in diets for Atlantic salmon. IMA substituted 25, 50 and $100 \%$ of FM in the control diet while IMB was used at 25 and $100 \%$ FM replacement rate. Diets containing IMA performed equally well as the control group at all inclusion levels, however diets produced with IMB reduced fish performance parameters already at 25\% FM replacement.

\subsection{Whole Body and Fillet Composition}

The influence of the use of IM on whole body composition (WBC) and fillet composition is not univocally. While an effect on the protein content has been shown (Belforti et al. 2015), the majority of the existing studies report a decrease in lipid and moisture increase in either WBC or fillet of fish when fed diets containing IM (St-Hilaire et al. 2007; Sealey et al. 2011; Kroeckel et al. 2012; Belforti et al. 2015). A reduced fat and energy digestibility of some IM could be the reason for the observed decreasing carcass fat content. Conversely, Akiyama et al. (1984) reported an increase in body energy reserves using earthworm. This effect was considered as very valuable as that could increase the fingerlings survival once released. Renna et al. (2017) found an increase of fat content in rainbow trout fillets using a partially defatted HI meal, but only at the highest level of inclusion. Similar results have been found in feeding Atlantic salmon diets containing high levels of defatted HI meal (Lock et al. unpublished results). High HI meal inclusion results in a higher saturated lipid content of the whole fish and fillet.

It has been ascertained that the dietary fatty acid (FA) profile dramatically influences the fish FA composition. IM are rich in saturated and monounsaturated FA, and do not contain the marine omega-3 long chain polyunsaturated FA (PUFA) such as eicosapentaenoic acid (EPA, C20:5 n3) or docosahexaenoic acid (DHA, C22:6 n3), which are well known for their beneficial effects on human health. St-Hilaire et al. (2007) reported a deterioration in fish nutritional quality using both MD and HI meals in diets for rainbow trout. The inclusion of IM led to a significant decrease of n3 FA such as EPA and DHA, which is confirmed in other studies (Belforti et al. 
2015; Gasco et al. 2016; Lock et al. 2016; Renna et al. 2017). Sealey et al. (2011) and Liland et al. (under revision) were able to modify the HI meal FA profile by enriching the larvae rearing substrate with fish offal and seaweed, respectively. Sealey et al. (2011) performed a trial with trout using the enriched HI meal and reported increased EPA (significant) and DHA (not significant) content in the fish. Up to $20 \%$ inclusion of a de-fatted $\mathrm{HI}$ meal while maintaining FO in the diet does not change the FA profile of trout compared to fish fed a control diet based on FM and FO (Renna et al. 2017).

\subsection{Sensory Analyses}

As the change of body composition and fatty acid profile can influence fish flavour, aroma and consumer acceptance (Turchini et al. 2011), some studies investigated the effect of diets containing IM on the sensory aspects of the fish fillet.

In a triangle difference test, untrained panellists did not highlight different sensory perception in samples of fillets of trout fed diets containing HI meal (enriched or not using fish offal in larva rearing substrate) compared to a FM based diet with no inclusion of HI pre-pupae meal (Sealey et al. 2011). Lock et al. (2016) investigated the sensory attributes of fillets of fish from diets containing FM (control) or $25 \%$ of inclusion of HI meal (100\% of FM substitution) after 105 days of feeding. Trained panellists were asked to score attributes such as odour, taste and flavour, and texture scoring them in a scale from 1 to 9 . The analysis did not highlight any significant differences in odour, flavour/taste or texture between groups.

Borgogno et al. (2017) utilised descriptive analysis (DA) and Temporal Dominance of Sensations (TDS) to investigate the effects of replacing 25 and $50 \%$ of FM with $\mathrm{HI}$ meal on sensory properties of rainbow trout. Results indicated that diets significantly affected fillets sensory profile. In fact, significant changes in perceived intensity of aroma, flavour and texture descriptors as a function of diet composition was indicated by DA. Concerning TDS, the first sensations perceived as dominant were related to texture attributes, followed by flavours. Dominance of fibrousness (or toughness) decreased with the increasing of HI meal in diet. Boiled fish, algae flavours and umami taste clearly dominated the fish fed control diet dynamic profile. The onset of metallic flavour dominance characterized fish fed diets where FM was substituted by 25 and $50 \%$ of HI meal. No differences in physical parameters were detected. Principal component analysis highlighted the relationship between sensory attributes and physico-chemical parameters. 


\subsection{Chitin}

It is commonly assumed that, due to its complex matrix, insect chitin is poorly digestible by fish, albeit the chitinase activity has been observed in some fish species (Henry et al. 2015). It has been hypothesized that these matrix forms of chitin may reduce the access of chitinases or proteinases to their substrates and thus prevent the absorption of proteins and lipids by the intestine. As such, reducing lipid and protein digestibility resulting in a subsequent reduction in nutrient utilization and fish growth performance (Belforti et al. 2015; Henry et al. 2015; Gasco et al. 2016). Some studies investigated the nutrient apparent digestibility coefficients (ADC) of diets containing IM. In general a lower crude protein ADC is found compared to FM based diets (Kroeckel et al. 2012; Belforti et al. 2015). Nevertheless, not all studies find a decrease in ADC (Lock et al. 2016; Renna et al. 2017), highlighting once again the high variability in type and quality of insect meal available on the market.

Chitin as a stimulant of intestinal function, much like a fibre, has also been suggested. The use of alternative protein sources has often showed to induce histological changes of the fish gastrointestinal tract (Merrifield et al. 2009; Gai et al. 2012; Oliva-Teles et al. 2015). Very few studies have investigated this aspect using insect meals and results obtained so far are promising as no negative effects are reported (Lock et al. 2016; Doğankaya 2017; Renna et al. 2017).

\section{Feed Safety}

Feed safety regulations are in place to secure that feed and feed materials do not pose any danger to human health, animal health or the environment, aiming to provide healthy and safe food products to the public. To achieve this, the European Union has set maximum allowed levels for undesirable substances in animal feed and feeding stuffs (EC Directive 2002/32 and amendments) (EU 2002). This covers a wide range of toxic compounds such as heavy metals, arsenic, polychlorinated biphenyl (PCBs), pesticides, plant and fungal toxins, amongst others. Safety considerations need to be taken into account when insects are destined to animal feed.

The uptake of contaminants by insects in the wild is well known, therefore they have been successfully used as bioindicators for environmental pollution (Azam et al. 2015). The chemical safety of farmed insects for feed and food purposes has been reviewed (Belluco et al. 2013; Charlton et al. 2015; van der Spiegel et al. 2013). Although little data is available, major potential chemical hazards associated with farmed insects are heavy metals, and in particular cadmium. Accumulation of metals in insects is dependent on species, life stage, and metal considered. Larval stages of insects have been shown to contain higher concentrations of metals than adults (Lindqvist 1992; Diener et al. 2015). 
Studies on the feed safety of farmed insects are very limited. Charlton et al. (2015) investigated a variety of insect species cultivated in several geographical locations, using different rearing substrates and conditions. The heavy metals cadmium, lead, mercury and the metalloid arsenic were found in larvae of MD, Blue bottle (Calliphora vomitoria), Blow fly (Chrysomya spp.) and HI. The EU maximum allowed levels for cadmium, lead, mercury and arsenic in complete fish feed and feed materials are set at $0.5,5,0.1,2$ and $2,10,0.1,2 \mathrm{mg} / \mathrm{kg}(88 \%$ dry matter), respectively (EU 2002). The concentrations of these undesirables in the fly larvae analysed by Charlton et al. (2015) were all below the maximum limits.

During rearing, insects could accumulate contaminants present in their feeding media. However, only few studies have investigated the influence of different feeding substrates on metal accumulation in insect larvae (Biancarosa et al. under revision; Diener et al. 2015; Vijver et al. 2003). HI larvae accumulate heavy metals when these are present in the diet, and a direct correlation exists between dietary and larval metal concentrations. This was shown using either feeding substrates spiked with heavy metals (cadmium, lead or zinc) (Diener et al. 2015) or media naturally containing these undesirable elements such as seaweeds (Biancarosa et al. under revision). Rearing insect larvae on substrates containing marine materials (seaweeds, tunicates, FM) resulted in the uptake of cadmium, lead, mercury and arsenic also in TM and super worms (Biancarosa et al. unpublished results). Vijver et al. (2003) previously documented accumulation of cadmium and lead in mealworms, when fed on soils contaminated with these contaminants.

The transfer of heavy metals and arsenic from feeding substrates to insect larvae highlights the need to carefully choose the material that is used to rear the larvae. However, there are currently big knowledge gaps related to the influence of different substrates on the metal content of farmed insects, thus further studies are required. Moreover, besides exploring the metal content of non-processed insects (e.g. whole larvae), documentation of the occurrence of these undesirable elements in processed larvae products (e.g. IM and insect lipid (IL)). Processing of the insect raw materials could potentially reduce metal contaminations prior to feeding. Further research is also needed to investigate whether heavy metals (or other potential risks) present in insects used for feed, are transferred to farmed fish.

Other chemical hazards may be present in rearing substrates for insects, thus may end up in insects and products thereof. In respect of the EU feed legislation (EC Directive 2002/32 and amendments) (EU 2002), Charlton et al. (2015) investigated the presence of dioxins, PCBs, polyaromatic hydrocarbons (PAHs), pesticide residues, veterinary drugs and mycotoxins in farmed insects destined to animal feed (house fly, blue bottle, blow fly and black soldier fly). These contaminants were found in the insect species tested, although in concentrations generally below current regulatory limits for these compounds in animal feed. Only the veterinary medicine nicarbazin $\left(4,4^{\prime}\right.$-dinitrocarbanilide) was detected at concentrations above the maximum allowed in animal feed $(500 \mu \mathrm{g} / \mathrm{kg})$ in one sample of MD due to the use of contaminated animal manure as growth medium for the larvae. Risks of this kind are minor in the EU, where feeding manure to farmed insects is currently prohibited. However, outside the EU other regulations apply. Insect meals produced 
outside the EU can be imported however they have to fulfil the same requirements set by the abovementioned EC Directive when used in feeds. For some of the compounds detected by Charlton et al. (2015) (e.g. PAHs and the pesticide residue chlorphyrifos), no maximum limits are currently established for animal feed.

Microbiological hazards related to the use of insects for feed purposes have been taken into account in the first "Risk profile related to the production and consumption of insects as food and feed" by EFSA (2009). Like other famed animals, microorganisms can be naturally associated with insects (e.g. the microbiota in the guts or on the surface), or can be introduced during rearing processes. However, very little studies on the microbiological safety of insects for food and feed are currently available (Klunder et al. 2012) to support such risk analysis.

\section{Conclusion}

Studies on IM inclusion in aquafeeds so far have focussed on FM replacement and growth performance, which is a logical first step for any new feed ingredient. Other aspects (both positive and negative) of IM on fish health are expected to be addressed over time, e.g. intestinal health, changes in microbiota, immunology, etc. There is also clearly an important role for insect processing (de-fattening, protein isolation, hydrolysation, etc), which can affect the properties of a meal into a great extent. The effect of chitin is still under investigation, and no conclusive evidence exists of chitin functioning as an anti-nutrient, immunostimulant, or any other function that has been proposed. Moreover, the role of the substrate on the quality of the meal is of a major importance as both the nutrient composition and content of undesirables are (partly) dictated by the composition of the insect feeding substrate. The approval of the EU Commission of the use of insect PAP in aquafeeds on the 13th December 2016 most likely triggers a surge in both demand and supply of IM and exiting developments in this field of research are expected. Signals from feed producers indicate a strong interest in using this resource if volumes are reaching 40.000 MT or more and the price is competitive. The increase in IM demand will inevitably lead to a decrease in IM selling price that is until now, still not competitive if compared with other protein sources commonly used in aquaculture feeds. Finally, initial studies on consumer acceptance of insect-fed fish showed a positive consumer attitude (Verbeke et al. 2015; Mancuso et al. 2016), but additional studies will be needed when insect products will reach the market. 


\section{References}

Akiyama T, Murai T, Hirasawa Y, Nose T (1984) Supplementation of various meals to fish diet for chum salmon fry. Aquaculture 37:217-222

Azam I, Afsheen S, Zia A, Javed M, Saeed R, Sarwar MK, Munir B (2015) Evaluating insects as bioindicators of heavy metal contamination and accumulation near industrial area of Gujrat, Pakistan. Biomed Res Int. https://doi.org/10.1155/2015/942751

Barroso FG, de Haro C, Sanchez-Muros MJ, Venegas E, Martínez-Sánchez A, Pérez-Bañón C (2014) The potential of various insect species for use as food for fish. Aquaculture 422-423:193-201

Belforti M, Gai F, Lussiana C, Renna M, Malfatto V, Rotolo L, De Marco M, Dabbou S, Schiavone A, Zoccarato I, Gasco L (2015) Tenebrio molitor meal in rainbow trout (Oncorhynchus mykiss) diets: effects on animal performance, nutrient digestibility and chemical composition of fillets. Ital J Anim Sci 14:670-675

Belluco $S$ et al (2013) Edible insects in a food safety and nutritional perspective: a critical review. Compr Rev Food Sci Food Saf 12(3):296-313

Biancarosa I, Liland N, Biemans D, Araujo P, Cruckner C, Waagbø R, Torstensen BE, Lock EJ, Amlund $\mathrm{H}$ (under revision) Uptake of heavy metals and arsenic in black soldier fly (Hermetia illucens) larvae grown on seaweed-enriched media. JIFF

Borgogno M, Dinnella C, Iaconisi V, Fusi R, Scarpaleggia C, Schiavone A, Monteleone E, Gasco L, Parisi G (2017) Inclusion of Hermetia illucens larvae meal on rainbow trout (Oncorhynchus mykiss) feed: effect on sensory profile according to static and dynamic evaluations. J Sci Food Agric. Accepted on December 03-2016. https://doi.org/10.1002/jsfa.819

Charlton AJ, Dickinson M, Wakefield ME, Fitches E, Kenis M, Han R, Zhu F, Kone N, Grant M, Devic E, Bruggeman G, Prior R, Smith R (2015) Exploring the chemical safety of fly larvae as a source of protein for animal feed. JIFF 1:7-16

Diener S, Zurbrügg C, Tockner K (2015) Bioaccumulation of heavy metals in the black soldier fly, Hermetia illucens and effects on its life cycle. JIFF 1:261-270

Doğankaya L (2017) Effects of fish meal substitution with Super worm (Zophobas morio) meal on growth performance of rainbow trout fingerlings. TrJFAS 32(1):1-7. https://doi.org/10.18864/ TJAS201701

EFSA (2009) Scientific opinion on arsenic in food EFSA panel on contaminants in the food chain (CONTAM). EFSA J:1351

EU (2002) Directive 2002/32/EC of the European Parliament and the Council of 7 May 2002 on undesirable substances in animal feed

Gai F, Gasco L, Daprà F, Palmegiano GB, Sicuro B (2012) Enzymatic and histological evaluations of gut and liver in rainbow trout, Oncorhynchus mykiss, fed with rice protein concentrate based diets. J World Aquacut Soc 43:218-229, ISSN: 0893-8849

Gasco L, Henry M, Piccolo G, Marono S, Gai F, Renna M, Lussiana C, Antonopoulou F, Mola P, Chatzifotis S (2016) Tenebrio molitor meal in diets for European sea bass (Dicentrarchus labrax L.) juveniles: growth performance, whole body composition and in vivo apparent digestibility. Anim Feed Sci Technol 220:34-45

Henry M, Gasco L, Piccolo G, Fountoulaki E (2015) Review on the use of insects in the diet of farmed fish: past and future. Anim Feed Sci Technol 203:1-22

Karapanagiotidis IT, Daskalopoulou E, Vogiatzis I, Rumbos C, Mente E, Athanassiou CG (2014) Substitution of fishmeal by fly Hermetia illucens prepupae meal in the diet of gilthead seabream (Sparus aurata). HydroMedit 2014, November 13-15, Volos, Greece

Klunder HC et al (2012) Microbiological aspects of processing and storage of edible insects. Food Control 26(2):628-631

Kroeckel S, Harjes AGE, Roth I, Katz H, Wuertz S, Susenbeth A, Schulz C (2012) When a turbot catches a fly: evaluation of a pre-pupae meal of the black soldier fly (Hermetia illucens) as fishmeal substitute-growth performance and chitin degradation in juvenile turbot (Psetta maxima). Aquaculture 364-365:345-352 
Liland N, Biancarosa I, Araujo P, Biemans D, Bruckner C, Waagbø R, Torstensen B, Lock EJ. (under revision) Modulation of nutrient composition of black soldier fly (Hermetia illucens) larvae by feeding seaweed-enriched media. JIFF

Lindqvist L (1992) Accumulation of cadmium, copper, and zinc in five species of phytophagous insects. Environ Entom 21(1):160-163

Lock EJ, Arsiwalla T, Waagbo R (2016) Insect larvae meal as an alternative source of nutrients in the diet of Atlantic salmon (Salmo salar) postsmolt. Aquac Nutr 22:1202-1213

Makkar HPS, Tran G, Heuze V, Ankers P (2014) State-of-the-art on use of insects as animal feed. Anim Feed Sci Technol 197:1-33

Mancuso T, Baldi L, Gasco L (2016) An empirical study on consumer acceptance of farmed fish fed on insect meals: the Italian case. Aquacult Int 24:1489-1507. https://doi.org/10.1007/ s10499-016-0007-z

Merrifield DL, Dimitroglou A, Bradley G, Baker RTM, Davies SJ (2009) Soybean meal alters autochthonous microbial populations, microvilli morphology and compromises intestinal enterocyte integrity of rainbow trout, Oncorhynchus mykiss (Walbaum). J Fish Dis 32:755-766

Oliva-Teles A, Enes P, Peres H (2015) Replacing fishmeal and fish oil in industrial aquafeeds for carnivorous fish. In: Davis DA (ed) Feed and feeding practice in aquaculture. Woodhead Publishing, Cambridge, pp 203-233

Piccolo G, Iaconisi V, Marono S, Gasco L, Loponte R, Nizza S, Bovera F, Parisi G (2017) Effect of Tenebrio molitor larvae meal on growth performance, in vivo nutrients digestibility, somatic and marketable indexes of gilthead sea bream (Sparus aurata). Anim Feed Sci Technol. https:// doi.org/10.1016/j.anifeedsci.2017.02.007

Renna M, Schiavone A, Gai F, Dabbou S, Lussiana C, Malfatto V, Prearo M, Capucchio MT, Biasato I, Biasibetti E, De Marco M, Zoccarato I, Gasco L (2017) Evaluation of the suitability of a partially defatted black soldier fly (Hermetia illucens $L$.) larvae meal as ingredient for rainbow trout (Oncorhynchus mykiss Walbaum) diets. J Anim Sci Biotechnol. (submitted)

Rumpold BA, Schülter OK (2013) Nutritional composition and safety aspects of edible insects. Mol Nutr Food Res 57:802-823

Sánchez-Muros MJ, Barroso FG, Manzano-Agugliaro F (2014) Insect meal as renewable source of food for animal feeding: a review. J Clean Prod 65:16-27

Sealey WM, Gaylord TG, Barrows FT, Tomberlin JK, McGuire MA, Ross C, St-Hilaire S (2011) Sensory analysis of rainbow trout, Oncorhynchus mykiss, fed enriched black soldier fly prepupae, Hermetia illucens. J World Aquacult Soc 42:34-45

St-Hilaire S, Sheppard C, Tomberlin JK, Irving S, Newton L, Mc Guire MA, Mosley EE, Hardy RW, Sealey W (2007) Fly prepupae as a feedstuff for rainbow trout, Oncorhynchus mykiss. J World Aquacult Soc 38:59-67

Turchini GM, Ng WK, Tocher DR (eds) (2011) Fish oil replacement and alternative lipid sources in aquaculture feeds. Taylor \& Francis/CRC Press, Boca Raton, p 533

van der Spiegel M, Noordam MY, van der Fels-Klerx HJ (2013) Safety of novel protein sources (Insects, microalgae, seaweed, duckweed, and rapeseed) and legislative aspects for their application in food and feed production. Compr Rev Food Sci Food Saf 12(6):662-678

Verbeke W, Spranghers T, De Clercq P, De Smet S, Sas B, Eeckhour M (2015) Insects in animal feed: acceptance and its determinants among farmers, agriculture sector stakeholders and citizens. Anim Feed Sci Technol 204:72-87

Vijver M, Jager T, Posthuma L, Peijnenburg W (2003) Metal uptake from soils and soil-sediment mixtures by larvae of Tenebrio molitor (L.) (Coleoptera). Ecotoxicol Environ Saf 54:277-289 


\section{Author Queries}

Chapter No.: 16 429379_1_En_16_Chapter

\begin{tabular}{|l|l|l|}
\hline Queries & Details Required & Author's Response \\
\hline AU1 & Please confirm corresponding author. & \\
\hline AU2 & Please provide the term for "FBW-IBW" definition. & \\
\hline AU3 & $\begin{array}{l}\text { Reference Lock et al. (unpublished results), Biancarosa et al. } \\
\text { (unpublished results) have been cited in text but not provided } \\
\text { in reference list. Please check. }\end{array}$ & \\
\hline AU4 & Please provide volume number for reference EFSA (2009). & \\
\hline AU5 & $\begin{array}{l}\text { Please provide volume and page range for reference Renna et } \\
\text { al. (2017). }\end{array}$ & \\
\hline
\end{tabular}

